\title{
JUSTIÇA SOCIOAMBIENTAL URBANA? REFLEXÕES ACERCA DOS PARQUES PÚBLICOS NO MUNICÍPIO DE SALVADOR, BAHIA
}

\author{
Rafaela Campos de Oliveira* \\ Juliana Campos de Oliveira**
}

\begin{abstract}
Resumo
Considera-se a possibilidade de concretude do Direito ao meio ambiente ecologicamente equilibrado (CF/88), na urbe, pelo acesso aos Parques Públicos Urbanos. Intenta-se questionar a integração urbana dos Parques Públicos soteropolitanos. A presença dos parques, nos bairros, agrega bem-estar ambiental, qualidade de vida aos cidadãos usuários. Porém, em Salvador, a política urbana adotada para gerir os Parques privilegia setores abastados trazendo questionamentos às garantias à dignidade da pessoa humana, aos direitos à sadia qualidade de vida e ao meio ambiente ecologicamente equilibrado e evidencia segregação, desfavorecendo efetivação da justiça socioambiental urbana. Utilizou-se metodologia de pesquisa bibliográfica primária/secundária.
\end{abstract}

Palavras-chave: Parques Públicos Urbanos; Sadia qualidade de vida; Segregação; Plano Diretor; Justiça socioambiental urbana.

\section{URBAN SOCIO-ENVIRONMENTAL JUSTICE? REFLECTIONS ABOUT PUBLIC PARKS IN SALVADOR CITY, IN BAHIA}

\begin{abstract}
It's possible to concretize the Right to an urban ecologically balanced environment, through access to Urban Public Parks. It's intended to question the urban integration of Public Parks in Salvador,Bahia. The presence of Parks adds environmental well-being, quality of life to citizens. However, in Salvador, the urban policy to manage the Parks privileges affluent sectors, questioning the guarantees to the human's dignity. It doesn't help the rights to a healthy quality of life in the city.This context evidences urban segregation, and it undermines the effectiveness of urban socio-environmental justice. It was used Primary and Secondary source as bibliographic research methodology.
\end{abstract}

Keywords: Urban Public Parks; Healthy quality of life; Segregation; Master Plan; Urban socio-environmental justice.

\footnotetext{
* Doutoranda em Arquitetura e Urbanismo pelo Programa de Pós-Graduação em Arquitetura e Urbanismo da Universidade Federal da Bahia (PPGAU/UFBA); Mestre em Arquitetura e Urbanismo pelo Programa de PósGraduação em Arquitetura e Urbanismo da Universidade Federal da Bahia (PPGAU/UFBA); Especialista em Direito Ambiental pela Fundação Faculdade de Direito da Universidade Federal da Bahia (FFD/UFBA); Graduada em Direito pela Universidade Estadual da Paraíba (UEPB). E-mail: rafinhabmcampos@ yahoo.com.br

${ }^{* *}$ Doutoranda em Arquitetura e Urbanismo pelo Programa de Pós-Graduação em Arquitetura e Urbanismo da Universidade Federal da Bahia (PPGAU/UFBA); Mestre em Direito Público pelo Programa de Pós-Graduação em Direito da Universidade Federal da Bahia (PPGD/UFBA); Especialista em Direito do Estado pela Fundação Faculdade de Direito da Universidade Federal da Bahia (FFD/UFBA); Graduada em Direito pela Universidade Estadual da Paraíba (UEPB).E-mail: juli.camposo@gmail.com
} 


\section{Introdução}

Nos dias atuais, os debates acerca da relação homem-natureza têm invadido os diversos campos de estudo e têm adquirido múltiplas nuances e especificidades.

No que se refere ao desenvolvimento urbanístico das cidades contemporâneas, podese observar o crescimento acelerado e não-planejado das cidades, em especial das metrópoles e cidades de médio porte, reproduzindo conflitos sociais, culturais bem como econômicos e ambientais.

Atendo-se à questão do meio ambiente natural presente nesses centros urbanos, vê-se que a natureza ora é degradada, hostilizada, ora organizada, planejada, adaptada, ou seja, urbanizada.

A urbanização de áreas naturais, ou áreas verdes, ocorre de várias formas, sejam artificiais, através da construção de praças, por exemplo, sejam através da melhoria da infraestrutura circundante a lagos, a trechos de matas, que se transformam em parques, tornando-se opção de lazer para os cidadãos, que deles usufruem.

A presente discussão pretende voltar-se, especificamente, às questões relativas à integração dos Parques Públicos Urbanos no cotidiano do município de Salvador, Bahia, e os possíveis reflexos à justiça socioambiental na urbe, oriundos desta inserção.

Para tanto, considerou-se que a presença dos Parques nos bairros, tende a representar fator agregador de bem-estar ambiental, opção de lazer, que contribui para a qualidade de vida dos cidadãos que deles podem usufruir. Entretanto, a localização destes equipamentos na capital baiana, aparentemente, tem privilegiado bairros nobres, em detrimento dos bairros periféricos e menos abastados.

Nesse diapasão, questionamentos acerca das garantias à dignidade da pessoa humana, bem como ao direito à sadia qualidade de vida, ao direito ao meio ambiente ecologicamente equilibrado, têm emergido, em meio ao quadro urbano que evidencia realidade de desigualdades, privilégios e segregações que parecem infindáveis e insolúveis e possivelmente se traduzem em aspectos de injustiça socioambiental na urbe.

$\mathrm{O}$ presente artigo pretende discutir tais questões utilizando-se de pesquisa bibliográfica de fontes primárias e secundárias, que retratam cenário soteropolitano existente em período anterior à Pandemia em curso, tendo como fundamentação-base a Constituição Federal Brasileira, o Estatuto da Cidade (Lei $n^{\circ}$ 10.257/01), o Plano Diretor do 
Desenvolvimento Urbano do Município de Salvador (Lei $n^{\circ}$ 6.069/16), além de fontes bibliográficas multidisciplinares que tratem do tema em discussão.

\section{A busca por sadia qualidade de vida urbana, por meio do direito ao meio ambiente ecologicamente equilibrado nas cidades}

Conforme preceitua o artigo 225, constante na Constituição Federal Brasileira de 1988, "todos têm direito ao meio ambiente ecologicamente equilibrado, bem de uso comum do povo e essencial à sadia qualidade de vida, impondo-se ao Poder Público e à coletividade o dever de defendê-lo e preservá-lo para as presentes e futuras gerações”.

De acordo com Machado (2009) cada ser humano só fruirá plenamente de um estado de bem-estar e de equidade se lhe for assegurado o direito fundamental de viver num meio ambiente ecologicamente equilibrado.

O reconhecimento do direito a um meio ambiente sadio configura-se como extensão do direito à vida, quer sob o enfoque da própria existência física e saúde dos seres humanos, quer quanto ao aspecto da dignidade dessa existência, a qualidade de vida, que faz com que valha a pena viver (MILARÉ, 2005).

Entretanto, atendo-se ao cotidiano observado nas médias e grandes cidades brasileiras, constata-se que, em sua grande maioria, estão passando por um período de acentuada urbanização, fato este que, embora por um lado represente progresso material, por outra vertente, abarca degradação da natureza, o que reflete negativamente na qualidade de vida de seus moradores (LOBODA \& ANGELIS, 2005).

A constante urbanização nos permite assistir, em nossos grandes centros urbanos, a problemas cruciais do desenvolvimento nada harmonioso entre a cidade e a natureza. Assim, podemos observar a substituição de valores naturais por ruídos, concreto, máquinas, edificações, poluição, o que ocasiona entre a obra do homem e a natureza crises ambientais cujos reflexos negativos contribuem para degeneração do meio ambiente urbano, proporcionando condições nada ideais para a sobrevivência humana (MORO , 1976, p. 15).

Machado (2009) considera que não basta viver ou conservar a vida, é justo buscar e conseguir a qualidade de vida. Sant'Anna (2011) coaduna com tal raciocínio reforçando que as condições de sobrevivência devem ter qualidade e serem sadias.

a saúde dos seres humanos não existe somente numa contraposição a não ter doenças diagnosticadas no presente. Leva-se em conta o estado dos 
elementos da Natureza - águas, solo, ar, flora, fauna e paisagem - para se aquilatar se esses elementos estão em estado de sanidade e de seu uso advenham saúde ou doenças e incômodos para os seres humanos (MACHADO, 2009, p.61).

O Estatuto das Cidades emerge, nesse contexto, como documento que fornece um instrumental a ser utilizado na ordenação dos espaços urbanos, com observância da proteção ambiental, e a busca de solução para problemas sociais graves, como déficit de moradia e de saneamento, que o caos urbano faz incidir, de modo contundente, sobre as camadas carentes da população.

A falta de planejamento, que considere os elementos naturais, é uma realidade agravante. Além do empobrecimento da paisagem urbana, são inúmeros e de diferentes amplitudes os problemas que podem ocorrer, em virtude da interdependência dos múltiplos subsistemas que coexistem numa cidade. Para que haja uma oferta de sadia qualidade de vida para a população é necessária a estruturação e realização de uma política urbana, condizente com os valores relativos à habitação, saneamento, meio ambiente, transporte, lazer, acesso e posse da terra. A qualidade de vida na urbe será garantida à medida que sejam respeitadas as funções sociais da cidade, provendo-se, ao mesmo tempo, o Direito à Cidade (SANT'ANNA, 2011).

A boa aparência das cidades surte, por exemplo, efeitos psicológicos importantes sobre a população, equilibrando, pela visão agradável e sugestiva de conjuntos e de elementos harmoniosos, a carga neurótica que a vida citadina despeja sobre as pessoas que nelas hão de viver, conviver e sobreviver (SILVA, 2010).

O cotidiano das cidades possibilita que a natureza seja vista como fonte de recuperação das energias. Por esta razão, como forma de tentar suprir a árida realidade das cidades, defende-se a existência de áreas verdes urbanizadas, através da construção e preservação de Parques Públicos Urbanos, por exemplo, para garantia do bem-estar ambiental a todos. Assim, a natureza que, num primeiro momento, apresentava-se como elemento estético, atualmente forma, junto à sociedade, um todo indissociável e difícil de ser separado (HENRIQUE, 2009).

A natureza se insere na cidade através dos jardins e praças, lugares para reis e nobres, para a aristocracia e burguesia. Só recentemente a população urbana se encontrará com a natureza na cidade através dos jardins e parques públicos, mas ainda pouco acessíveis para todos. A disposição destes jardins e parques públicos no espaço intra-urbano atende as lógicas da especulação 
imobiliária e da renda. Mesmo cidades brasileiras com áreas verdes consideráveis apresentam uma concentração destas áreas nos bairros nobres. $\mathrm{Na}$ maioria dos bairros da periferia social e de ocupação popular, altamente adensados, são inexistentes áreas públicas, verdes e de lazer (IDEM, p. 118).

Para José Afonso da Silva (2010), as áreas verdes atuam como exigência higiênica, de equilíbrio do meio ambiente urbano e de locais de lazer. As áreas verdes

\begin{abstract}
quando bem distribuídas no traçado urbano, oferecem colorido e plasticidade ao meio urbano. A arborização das vias públicas, além da atenuação de ruídos, da fixação e retenção do pó, da reoxigenação do ar (como as áreas verdes), de oferecer frescura e projetar sombras, embeleza-as. Como em tudo o mais que diz com o urbanismo, também aqui não se há de cair no esteticismo gratuito, vazio,(...) Sem suprimir o que possa ter de pitoresco, a vegetação deve empregar-se como um critério realista e não-romântico. As árvores, os arbustos, os prados e as flores devem ser empregados com um critério racional, destinado a preencher função social assinada aos espaços verdes, dentro da qual, e sem sair-se dela, terão cabimento os diversos critérios decorativos e de ornamento (IDEM, p. 306).
\end{abstract}

\title{
3. Parques Públicos Urbanos em Salvador frente aos instrumentos norteadores de política urbana
}

Pode-se dizer que para a transformação de uma realidade urbana insatisfatória, faz-se necessário que o Estado seja munido de instrumentos que o permitam atuar nesta transformação, de forma eficiente. Um destes instrumentos é o planejamento (SANT'ANNA, 2011), que, em geral, é um processo técnico, instrumentado para transformar a realidade existente, no sentido de objetivos previamente estabelecidos (SILVA, 2010).

A possibilidade de se instaurar novas práticas de planejamento e gestão urbana no Brasil, em bases jurídicas, urbanísticas e financeiras mais sólidas, tornou-se mais factível desde a Constituição de 1988 e posterior aprovação do Estatuto da Cidade, em 2001 (MATOS, 2008).

O Estatuto da Cidade, entre outros caracteres, requalifica, fundamenta juridicamente, estabelece instrumentos e dá consistência técnica aos Planos Diretores urbanísticos. Entre suas premissas, o Estatuto caracteriza-se por estabelecer a necessidade de implantação da Participação Popular enquanto instrumento norteador dos Planos Diretores, buscando a constituição de um ideal participativo e inclusivo como parte do projeto de democratização (SANTOS, 2002).

Nesse sentido, admite-se que o processo do planejamento urbano adquire sentido jurídico quando se traduz em planos urbanísticos. A função urbanística, em sua atuação mais 
concreta e eficaz, é exercida num nível municipal através dos planos de desenvolvimento urbano, ou planos diretores.

De acordo com o artigo 182 da Constituição Federal Brasileira de 1988, o Plano Diretor assume a função de instrumento básico da política urbana do Município, que tem por objetivo ordenar o pleno desenvolvimento das funções sociais da cidade e garantir o bemestar da comunidade local.

A função social de uma determinada cidade compreende o oferecimento efetivo e de boas condições de moradia, transporte, recreação e condições satisfatórias de trabalho aos seus moradores, para que o bem-estar seja alcançado por todos (SANT'ANNA, 2011; ALFONSIN, 2008).

Nesse sentido, considerando-se as necessidades básicas do homem, existem funções essenciais que toda cidade deve atender para bem servir aos seus cidadãos. São elas: habitar, trabalhar, recrear e circular.

Restringindo-se à função recreativa, observa-se que as áreas verdes e Parques se constituem como exemplo de equipamentos urbanos que, além de desempenharem as funções ambientais, preservacionistas e estéticas, certamente, se apresentam enquanto áreas de lazer para as populações, cumprindo funções sociais, educativas e recreativas.

O Parque Público Urbano, como modelo de planejamento urbano, espalhou-se por todas as grandes metrópoles mundiais. Considera-se, no entanto, que apesar das similaridades formais e funcionais evidentes nesses espaços de lazer, existem diferenças fundamentais nas práticas espaciais dos seus usuários (SERPA, 2011).

No que se refere ao município de Salvador, a distribuição, bem como a frequentação dos Parques e Jardins Públicos, podem revelar as nuances da organização socioespacial da metrópole.

As particularidades dos espaços públicos recreativos, em Salvador, em especial, dos Parques Públicos, residem na leitura que se pode fazer deles em termos de visibilidade. Agentes públicos e privados vêm conduzindo, depois dos anos de 1990, uma política urbana que consiste na encenação desses espaços, que passam a desempenhar um papel de "vitrine" no contexto urbano. Nesses espaços, a natureza tem sido encenada e consumida (IDEM).

Os Parques Públicos mais centrais são mais visíveis na paisagem urbana sendo, portanto, alvo de políticas públicas de melhoria, enquanto os mais distantes dos bairros mais prósperos não são objeto de qualquer tipo de intervenção. 
enquanto alguns parques são extremamente pobres em cobertura vegetal, não possuindo também nada de excepcional em termos de qualidade estética, e representam um papel significativo na cena urbana, outros, preciosos em termos ecológicos, não recebem qualquer tipo de projeto ou intervenção (SERPA, p. 92).

Esta situação é vivenciada em Salvador, por carência de uma gestão municipal democrática em matéria ambiental. Petrucci (2011) esclarece que os objetivos fundamentais de uma Política Urbana, consistente em ordenar o pleno desenvolvimento das funções sociais da cidade e garantir o bem-estar dos seus habitantes, são atingidos quando se realiza gestão municipal democrática.

Scheinowitz (1998) acrescenta, no que se refere especificamente à proteção ambiental no ambiente urbano, a necessidade de que o urbanismo seja não linear, adequandose às particularidades setoriais de uma metrópole, como Salvador, através da construção de Planos Diretores referentes a subsetores da cidade, como meio de valorização do meio ambiente natural.

O mais recente Plano Diretor de Salvador (Lei $n^{\circ}$ 9.069/16), sancionado pela Prefeitura em 30 de junho de 2016, dispõe de 411 artigos, que tratam do zoneamento da cidade e das especificações econômico-sociais de cada área.

No entanto, de acordo com Heliodório Sampaio (2010), a legislação urbanística local costuma ser ambígua e vem sendo alterada de forma a beneficiar as alianças entre interesses políticos e o mercado imobiliário. As atividades burladoras dos Planos Diretores, a corrupção no uso do solo, que representam desacordo com os preceitos democráticos de gestão, têm desacreditado as normas instituídas e os órgãos responsáveis pelo controle urbanístico das cidades.

Sob este viés, considera-se que a ideia de "plano urbanístico" como instituto jurídico capaz de viabilizar políticas públicas de inclusão socioespaciais e ambientais merece discussão profunda, cabendo ressaltar que os Planos Diretores brasileiros têm sido alvo de severas críticas (FERNANDES, 2008).

De modo geral, subsidiados por modelos importados, os Planos Diretores têm se apoiado em correntes distantes da complexa realidade dos habitantes a quem se dirigem. Tais Planos têm sido, portanto, incapazes de atender às peculiaridades das cidades brasileiras (MATOS, 2008). 
Frequentemente, estes Planos estão recheados por conteúdo extremamente técnico, com linguajar rebuscado, inacessível à população geral, e, em alguns casos, insipiente acerca do contexto a que pretendem se referir, por serem desvinculados dos fatos, da real condição das cidades brasileiras em que se inserem. Observa-se, constantemente, a utilização de modelos genéricos, superficialmente adaptados às particularidades de cada cidade. Sob este viés, convém citar a analogia ao pensamento de Galileu, acerca da astronomia de Ptolomeu, proposta por Villaça (2012, p.209): “o Plano Diretor está de acordo com a filosofia, mas (...) não parece estar de acordo com os fatos".

\begin{abstract}
Assim, para muitos, é um mito a ideia de que os Planos Diretores sejam instrumentos fundamentais para guiar o desenvolvimento da cidade. (...) No longo prazo, dissolvem-se os 'pactos territoriais' diluídos numa vontade política que se concentra nestes pontos cruciais do planejamento urbano e do urbanismo apenas nos períodos eleitorais (SAMPAIO, p.114).
\end{abstract}

Nesse sentido, um instrumento urbanístico mesmo que bem elaborado, caso apresente efetividade reduzida, irá repercutir pouco na transformação das dinâmicas urbanas do mercado imobiliário. Há carências observáveis, antes mesmo da promulgação dos Planos Diretores, inclusive porque a Constituição brasileira é tímida, em relação a questões urbanas, como por exemplo, no enfrentamento do obstáculo que a apropriação privada do solo urbano pode representar ao planejamento e à política urbana. O Estatuto da Cidade, por seu turno, embora apresente avanços, se configura em Lei carecedora de maior divulgação, reconhecimento e efetividade, tanto por parte dos Poderes Públicos, quanto pela Academia e pelo Judiciário (ALFONSIN, 2008).

Urge considerar-se a necessidade de que surjam novas formas de compreensão do planejamento urbano, em particular, do seu compromisso com a justiça socioambiental. A partir de interpretação do Estatuto da Cidade, que seja mais contemporânea e adaptada ao atual contexto das cidades e atuais demandas socioambientais, é possível detectar princípios que possam nortear a política urbana, em favor da promoção da função socioambiental da cidade. Faz-se mister a emergência de uma nova ordem jurídico urbanística, onde sejam reconhecidos, entre outros direitos coletivos, no meio urbano, o direito à preservação ambiental, considerando, ainda, a importância do urbanismo, entendido como uma função pública em sentido amplo (FERNANDES, 2006). 


\section{Salvador: Segregação nos Parques Públicos enquanto entrave à Justiça socioambiental}

No contexto urbano, a grande maioria da população brasileira tem sido privada de boa qualidade de habitação, trabalho, transporte e lazer. O bem-estar de todos e a sadia qualidade de vida previstos na Constituição Federal de 1988, até então, frequentemente, têmse mostrado como letras estáticas sobre um papel (SANT'ANNA, 2011).

Adicione-se, as ofertas de lazer, nas cidades, relacionadas a um ambiente natural e saudável, têm sido insuficientes, ou quase inexistentes em algumas áreas. Os valores sociais distorcidos têm feito que os shoppings sejam considerados espaços de lazer. No entanto, nestes locais, é bem verdade, para se divertir, é preciso consumir. Parques, praças e áreas livres, onde o desfrute de uma vida saudável não seja relacionado ao status social, têm se tornado exíguos, nas grandes cidades brasileiras (IDEM, p.128).

Sangodeyi-Dabrowski (2003, p.165) afirma que alguns ideólogos brasileiros consideram que o Brasil caracteriza-se como uma "democracia racial". Nesse contexto, podese dizer que Salvador tem obedecido a esta tendência, configurando-se como uma cidade dual. Nela, o espaço se divide em dois: há um circuito superior, moderno, onde as classes média e superior são predominantes, e um circuito inferior, quase que exclusivamente destinado aos pobres, desprezados e abandonados pelos poderes públicos, sofrendo ostensiva falta de serviços básicos (SANTOS, 1979). Ainda que as classes sociais estejam espacialmente próximas, é como se constituíssem dois mundos superpostos que nunca se encontram, embora se observem mutuamente (SANGODEYI-DABROWSKI, 2003).

Gordilho-Souza (2008, p. 264) atenta para a intensificação e o surgimento de formas de segregação das classes sociais no espaço da cidade, configurando, na atualidade, além de uma marcante separação entre pobres e ricos, uma forte exclusão dos direitos urbanísticos "cidades" distintas para "cidadãos" diferenciados.

Neste sentido, Salvador, como outras metrópoles do Brasil e do mundo, vem conduzindo políticas de requalificação urbana seletivas e segregacionistas, que reforçam e tornam visíveis as desigualdades socioespaciais sobre o tecido urbano-metropolitano (SERPA, 2008).

Depois da segunda metade dos anos de 1990, a cidade de Salvador empreendeu uma política sistemática de criação e reabilitação de Parques e Jardins Públicos. Entretanto esses programas não têm atendido, via de regra, às áreas periféricas e de urbanização popular da 
cidade, onde o abandono de Parques e Praças é notório (IDEM). Henrique (2009, p.109) afirma que "nos bairros dos excluídos observa-se a natureza relegada 'ao mato' ou 'às enchentes' e, em muitos lugares, observa-se total falta de qualquer natureza".

embora o Programa de Recuperação das Áreas Degradadas de Salvador e dos Parques Metropolitanos seja uma tentativa de repensar a cidade em termos urbanísticos, o que vem sendo priorizado pela Conder é a vocação turística da capital baiana, com a valorização de grandes parques, próximos à orla marítima (a exemplo do parque do Abaeté, Costa Azul e Jardim dos Namorados). O programa não atende, porém, áreas periféricas da cidade, onde o abandono das praças e parques é notório, a exemplo do Parque de São Bartolomeu, localizado no Subúrbio Ferroviário de Salvador, que, apesar de constituir-se numa importante reserva de mata atlântica e espaço sagrado para os praticantes do candomblé, encontra-se totalmente abandonado (SERPA, 2003, p.125).

Diante de tal realidade, pequena parcela da população se beneficia da reabilitação de parques e jardins públicos nesta cidade. Serpa (2011, p.51) acrescenta que "a população de baixa renda não dispõe de carro particular nem de transporte coletivo eficiente. Assim, os novos equipamentos - em geral distantes dos bairros periféricos - vêm segregar ainda mais os mais humildes".

O modo de produção capitalista, ao favorecer a propriedade privada, tem feito da natureza estratégia de marketing. A natureza torna-se objeto de consumo que, pela escassez, transfigura-se em mercadoria de luxo, produzida e consumida através de ideia utilitarista. Nos usos humanos da natureza, esta deixa de ser reconhecida como algo em si mesma.

A disposição dos jardins e parques públicos no espaço intraurbano atende às lógicas da especulação imobiliária e da renda. Para o autor,

a natureza na cidade é uma necessidade que infelizmente foi engolida e propagada pelas possibilidades de consumo da moradia. As necessidades estão sendo criadas de acordo com a renda do comprador dos imóveis. Assim, a natureza na cidade torna-se uma mercadoria para poucos consumidores, escolhida em função do aumento do valor de troca dos empreendedores imobiliários. Para os agentes do mercado imobiliário, a natureza na cidade não é uma necessidade coletiva, e a exclusão é exercida a serviço da acumulação (HENRIQUE, 2009, p.133).

Serpa admite que

na Salvador contemporânea, como em outras metrópoles do mundo ocidental, os espaços públicos urbanos são meios de controle social, sobretudo das novas classes médias, destino final das políticas públicas, que, em última instância, procuram multiplicar o consumo e valorizar o solo urbano nos locais onde são aplicadas (SERPA, 2008, p.183). 
A definição da natureza na cidade como uma mercadoria destinada a atender aos anseios das classes dominantes implica a exclusão das classes economicamente inferiores do acesso à vida com a natureza (HENRIQUE, 2009). Tal situação caracteriza a segregação social e ambiental urbana, tão presente no contexto urbano do Município de Salvador.

O exame dessa realidade, vista pelo ângulo da distribuição de grandes equipamentos urbanos concentradores de trabalho (...), bem como das facilidades de acesso viário, infra-estrutura e distribuição de áreas verdes e de lazer, enfim, outros indicadores de conforto urbano, demonstra que a exclusão urbanística se manifesta de forma muito mais profunda. A exclusão da maioria da população dessas vantagens coletivas dificulta a possibilidade de sua inserção na dinâmica urbana mais ampla, ou seja, o habitar na cidade beneficiada. (...) A cidade cresceu, neste século, para atingir um ambiente construído fisicamente complexo, caótico, maltratado, de desrespeito aos recursos naturais e, na questão socioespacial, marcado por uma intensa segregação de renda, conjugada a uma ampla exclusão dos benefícios urbanísticos - uma cidade sem cidadania. Enfim, um quadro de difícil intervenção para sua melhoria, que desafia novas formas de pensar e de intervir na cidade (GORDILHO-SOUZA, 2008, p. 263-265).

Diante deste cenário de segregação socioambiental estabelecido em Salvador, se faz necessário adotar formas materiais de mudar o quadro classista, excludente e segregador em que se encontra a natureza na cidade.

Para tanto, é indispensável o entendimento de que a natureza na cidade seja para e de todos, independentemente do poder aquisitivo, e que exista a instauração da apropriação da natureza na cidade sob a égide do conceito de valor de uso e não de valor de troca (HENRIQUE, 2009).

Urgem providencias em direção à transformação. Para tanto, é necessário conscientizar a população e seus dirigentes, além de cobrar a atuação do Poder Público de forma holística.

Deve-se pensar em uma cidade para todos, com planejamento urbano e voltada para o bem-estar das pessoas, mesmo porque, o mundo moderno em que se vive, após a expansão do capitalismo, é um mundo onde a cidade se acrescenta, toma dimensões novas, torna-se mais complexa, centralizando a vida do conjunto, ou seja, da humanidade (SOUZA, 2010).

A população majoritária no município de Salvador tem sido representada pela classe economicamente instável e desfavorecida. O território da pobreza urbana não se refere a uma minoria excluída ou marginal, mas em algumas cidades (como, por exemplo, Salvador) compreende a maioria da população (MARICATO, 2011). 
Esta parcela da sociedade urbana também merece ter seus direitos respeitados e garantidos, dentre os quais, o direito ao meio ambiente ecologicamente equilibrado, à sadia qualidade de vida, à dignidade da pessoa humana.

Pode-se dizer que a qualidade de vida encontra-se associada ao bem-estar das pessoas e à dignidade humana (...) a vida digna com qualidade representa, certamente, o fim maior a ser colimado pelo direito em benefício do ser humano. (...) Garantir a qualidade de vida é preservar a dignidade humana. O bem maior protegido pelo direito é a vida humana. Mas o ser humano, ser racional, é sujeito consciente das situações que vivencia (...) Precisa, portanto, de algo mais do que sobreviver: precisa viver com dignidade (SOUZA, 2010, p. 50-51).

Os Parques Públicos Urbanos existem, ou assim deveria ser, para preencher, de certa forma, esta lacuna. Harvey (1982, p.28) ressalta que "o apego a algum sentido de relação não alienada com a natureza faz a vida suportável para o trabalhador”. Torna-se indispensável, portanto, questionar, na prática, se este objetivo está sendo alcançado, ou melhor, se tem se buscado alcançá-lo.

Existe uma realidade urbanística excludente, no município de Salvador, que privilegia uma minoria, responsável por ensejar segregação e atuando como entrave à justiça socioambiental urbana? Diante do exposto, sim, existe. Assim sendo, os cidadãos não deveriam se manifestar para impedir que esta situação se perdure? O meio acadêmicocientífico não seria uma forma adequada de investigar e discutir aprofundadamente tal realidade?

As discussões referentes à garantia de um meio ambiente ecologicamente equilibrado para todos, à sadia qualidade de vida, à dignidade da pessoa humana e à busca por justiça socioambiental e urbana, pelo seu compromisso com o desenvolvimento urbano democrático e com a efetividade do Direito à Cidade, não podem estar alheias a tais debates.

\section{Conclusões}

$\mathrm{Na}$ atual conjuntura urbana, presenciam-se diversidades sociais múltiplas. Desigualdades social, cultural, étnica, associadas às inadequadas políticas públicas, bem como às dificuldades de efetivação de diversos direitos inerentes à dignidade da pessoa humana, são alguns exemplos.

Nesse contexto, tornar o direito à natureza nas cidades, um direito de todos, tem se constituído em desafio que se propõe aos diversos setores de estudo, sejam eles jurídicos, 
técnicos, sociais, urbanísticos, enquanto compromisso com a efetivação da justiça socioambiental e urbanística. A preocupação em disponibilizar o acesso a um meio ambiente ecologicamente equilibrado tem, cada vez mais, se tornado uma constante nos estudos referentes ao urbanismo e ao direito à sadia qualidade de vida nas cidades.

Esta temática é presenciada no Estatuto das Cidades e nos Planos Diretores de Desenvolvimento Urbano dos municípios brasileiros.

Entretanto, embora reconheçam-se os Planos Urbanísticos como institutos jurídicos capazes de viabilizar políticas públicas promotoras de inclusão e justiça socioespacial e ambiental, nas cidades, observa-se que a aplicabilidade da previsão legal, nas Políticas Públicas Urbanas, tem sido deficiente, razão por que os Planos Diretores têm sido alvo de severas críticas, merecendo, portanto, discussões profundas, no sentido de promover melhor adequação da norma ao contexto particular de cada cidade.

Verifica-se que as Políticas Públicas urbanísticas relativas ao acesso dos cidadãos à natureza, particularmente no município de Salvador, têm privilegiado o mercado imobiliário. O modo de produção capitalista, preponderante no cenário urbano nacional, tem ensejado o estabelecimento de diversos modos de segregação nas cidades, em especial, nas metrópoles regionais.

Adicione-se que, diante dos quadros de degradação ambiental, em prol do crescimento urbano, tem existido tendência a lidar-se com a natureza como mercadoria rara, cara e, portanto, acessível à parcela da população detentora de alto poder aquisitivo.

Em Salvador, observa-se que os Parques Públicos não estão distribuídos de forma justa e proporcional, no tecido urbano, considerando-se que há escassez de Parques Públicos nos bairros periféricos. Sendo assim, há tendência à instalação de Parques Públicos em setores considerados nobres da cidade, o que proporciona privilégios em termos de bem-estar ambiental à pequena parcela da população residente em áreas próximas, em detrimento de imensa maioria de pessoas que habitam bairros longínquos, desprovidas de recursos financeiros que as possibilitem usufruir da natureza distante.

Evidencia-se, adicionalmente, o descaso da Administração Pública local em cuidar, sanear, quando existentes, os Parques Públicos localizados em setores predominantemente ocupados por moradores com baixo poder aquisitivo. Tal situação pode ser caracterizada como segregação social e ambiental urbana. 
O município de Salvador evidencia, portanto, segregação socioambiental, ferindo o Dispositivo Constitucional que garante a todos o direito ao meio ambiente ecologicamente equilibrado, maculando as aspirações em se obter justiça socioambiental no ambiente urbano.

\section{Referências}

ALCÂNTARA, Adriana. Questionamentos sobre a praça contemporânea. In:

CAVALCANTE, Marília; OLMOS, Susana (orgs.). Olhares sobre a paisagem: um estudo de caso. Salvador: Edufba, 2008.

ALFONSIN, Betânia de Moraes. A Política Urbana em disputa: desafios para a efetividade de novos instrumentos em uma perspectiva analítica de Direito Urbanístico Comparado (Brasil, Colômbia e Espanaha). Tese (Doutorado em Planejamento Urbano e Regional). Programa de Pós-Graduação em Planejamento Urbano e Regional, Unversidade Federal do Rio de Janeiro, Rio de Janeiro, 2008.

BENJAMIN, Antônio Herman de Vasconcellos e. Constitucionalização do Ambiente e Ecologização da Constituição Brasileira. In: CANOTILHO,José Joaquim Gomes; LEITE, José Rubens Morato (Orgs.). Direito Constitucional Ambiental Brasileiro. São Paulo: Saraiva, 2007, p. 57-130

BENJAMIM, Antônio Herman de Vasconcellos e. Função Ambiental. Dano Ambiental, Prevenção, Reparação e Repressão. São Paulo: Revista dos Tribunais, 1993.

BRASIL. Constituição (1988). Constituição da República Federativa do Brasil. Brasília: Disponível em: <http://www.presidenciadarepublica.gov.br/>, 1988. Acesso em 29.09.20.

Lei n. 10.257, de 10 de jul. 2001. Dispõe sobre o Estatuto das Cidades e dá outras providências. Disponível em:

<http://www.presidenciadarepublica.gov.br/>. Acesso em 29.09.20.

. Lei n. ${ }^{\circ}$ 9.069, de 30 de jun. 2016. Dispõe sobre o Plano Diretor de Desenvolvimento Urbano do Município de Salvador, e dá outras providências. Disponível em:

< https://leismunicipais.com.br/plano-diretor-salvador-ba-2016-06-30-versao-original > Acesso em: 29.09.20.

CARVALHO, Inaiá Maria Moreira de; PEREIRA, Gilberto Corso. As “cidades" de Salvador. In: CARVALHO, Inaiá Maria Moreira de; PEREIRA, Gilberto Corso (orgs.). Como anda Salvador e sua região metropolitana. Salvador: Edufba, p. 81 - 107, 2008.

DINIZ. Maria Helena. Dicionário Jurídico. São Paulo: Saraiva, v. 2, 1998

EMÍDIO, Teresa. Meio Ambiente e Paisagem. São Paulo: Senac, 2006. 
FERNANDES, Ana. Consenso sobre a cidade? In: ESTEVES JUNIOR, Milton; URIARTE, Urpi Montoya (orgs.). Panoramas Urbanos: reflexões sobres a cidade. Salvador: Edufba, p. 71-81, 2003.

FERNANDES, Edésio. A nova ordem jurídico-urbanística no Brasil. In: FERNANDES, Edésio; ALFONSIN, Betânia de Moraes (org.). Direito Urbanístico: estudos brasileiros e internacionais. Belo Horizonte: Del Rey, 2006.

Reforma urbana e reforma jurídica no Brasil: duas questões para reflexão. In: COSTA, Geraldo Magela; MENDONÇA, Jupira Gomes de (orgs.). Planejamento urbano no Brasil trajetória, avanços e perspectivas. Belo Horizonte: C/Arte, p. 123-135, 2008.

FERREIRA, Aurélio Buarque de Holanda. Miniaurélio: o minidicionário da língua portuguesa. 7. ed. Curitiba: Positivo, 2009

FIORILLO, Celso Antônio Pacheco. Curso de Direito Ambiental brasileiro. 5. Ed. São Paulo: Saraiva, 2004

GIACOMINI-FILHO, Gino. Meio Ambiente e Consumismo. São Paulo: Senac, 2008.

GIL, Antônio Carlos. Métodos e Técnicas de Pesquisa Social. 5. Ed. São Paulo: Atlas, 1999

GORDILHO-SOUZA, Angela. Limites do habitar: segregação e exclusão na configuração urbana contemporânea de Salvador e perspectivas no final do século XX. 2. ed. Salvador: Edufba, 2008.

HARVEY, David. O trabalho, o capital e o conflito de classes em torno do ambiente construído nas sociedades capitalistas avançadas, Espaço \& Debates: Revista de Estudos Regionais e Urbanos. São Paulo, n. 6, p. 6-35, 1982.

HENRIQUE, Wendel. O Direito à Natureza na Cidade. Salvador: Edufba, 2009.

LEITE, José Rubens Morato; AYALA, Patryck de Araújo. Dano Ambiental: do individual ao extrapatrimonial. 3. Ed. São Paulo: Revista dos Tribunais, 2010

2002

. Direito Ambiental na Sociedade de Risco. Rio de Janeiro: Forense Universitária,

LOBODA, Carlos Roberto; ANGELIS, Bruno Luiz Domingos De. Áreas verdes públicas urbanas: conceito, usos e funções. Ambiência. Guarapuava: Unicentro, n. 1, p. 125-139, 2005 .

MACHADO, Paulo Afonso Leme. Direito Ambiental Brasileiro. 17. Ed. São Paulo: Malheiros, 2009

MARCUSE, Peter. Enclaves, sim; Guetos, não: a segregação e o Estado. Espaço e Debates, Revista de Estudos Regionais e Urbanos. São Paulo: Neru, n. 45, p. 24-33, 2004. 
MARICATO, Ermínia. Metrópole na periferia do Capitalismo. São Paulo: Hucitec, 1996. . Ermínia. O impasse da política urbana no Brasil. Petrópolis: Vozes, 2011.

MATOS, Ralfo Edmundo da Silva. Plano Diretor, gestão urbana e participação: algumas reflexões. In: COSTA, Geraldo Magela; MENDONÇA, Jupira Gomes de (orgs.). Planejamento urbano no Brasil trajetória, avanços e perspectivas. Belo Horizonte: C/Arte, p. 156-168, 2008.

MILARÉ, Édis. Direito do Ambiente. 4. Ed. São Paulo: Revista dos Tribunais, 2005.

MORO, Dalton Áureo. As áreas verdes e seu papel na ecologia urbana e no clima urbano. Revista UNIMAR. Bauru: Unimar, n. 2, p. 15 - 20, 1976.

NORMA BRASILEIRA. ABNT NBR 14724. Informação e Documentação - Trabalhos Acadêmicos - Apresentação. 2. ed. Rio de Janeiro, 2005.

OLIVEIRA, Bernardete Campos. Impacto de práticas agrícolas sobre mananciais, alimentos e qualidade de vida. Dissertação (Mestrado em Saúde Coletiva) - Centro de Ciências Sociais e da Saúde, Universidade Estadual da Paraíba, Campina Grande, 2001.

PETRUCCI, Jivago. Gestão Democrática da Cidade - delineamento constitucional e legal. In: DALLARI, Adilson Abreu; DI SARNO, Daniela Campos Libório (coord.). Direito Urbanístico e Ambiental. Belo Horizonte: Fórum, p. 151 - 175, 2011.

SANGODEYI-DABROWSKI, Delphine. As raízes ideológicas da segregação no Brasil: o exemplo de Salvador. In: ESTEVES JUNIOR, Milton; URIARTE, Urpi Montoya (orgs.). Panoramas Urbanos: reflexões sobres a cidade. Salvador: Edufba, p. 165 - 184, 2003.

SANTOS, Boaventura de Sousa. Democratizar a democracia: os caminhos da democracia participativa. Rio de Janeiro: Civilização Brasileira, 2002.

SANTOS, Milton. O Espaço Dividido:os dois circuitos da economia urbana nos países subdesenvolvidos. Rio de Janeiro: Francisco Alves, 1979.

SAMPAIO, Antônio Heliodório Lima. 10 necessárias falas: cidade, arquitetura e urbanismo. Salvador: Edufba, 2010.

SANT'ANNA, Mariana Senna. Planejamento Urbano e Qualidade de Vida - da Constituição Federal ao Plano Diretor. In: DALLARI, Adilson Abreu; DI SARNO, Daniela Campos Libório (coord.). Direito Urbanístico e Ambiental. Belo Horizonte: Fórum, p. 117 - 136, 2011.

SCHEINOWITZ, A. S. O macroplanejamento da aglomeração de Salvador. Salvador: Secretaria da Cultura e do Turismo - EGBA, 1998. 
SERPA, Angelo. Apropriação social versus requalificação dos parques e praças na capital baiana. In: ESTEVES JUNIOR, Milton; URIARTE, Urpi Montoya (orgs.). Panoramas Urbanos: reflexões sobres a cidade. Salvador: Edufba, p. 121 - 139, 2003.

Os espaços públicos da Salvador contemporânea. In: CARVALHO, Inaiá Maria Moreira de; PEREIRA, Gilberto Corso (orgs.). Como anda Salvador e sua região metropolitana. Salvador: Edufba, p. 173 - 188, 2008.

O espaço público na cidade contemporânea. SaoPaulo: Contexto, 2011.

SILVA, José Afonso da.Direito Urbanístico Brasileiro. 6. ed. São Paulo: Malheiros, 2010.

SIRVINSKAS, Luís Paulo. Manual de Direito Ambiental. 3. ed. São Paulo: Saraiva, 2005.

SOUZA, Demétrius Coelho. O meio ambiente das cidades. São Paulo: Atlas, 2010.

VILLAÇA, Flávio. A segregação urbana e a Justiça. Revista Brasileira de Ciências Criminais, São Paulo: Revista dos Tribunais, n. 44, p.341-346, 2003.

Reflexões sobre as cidades brasileiras. São Paulo: Studio Nobel, 2012.

VASCONCELOS, Pedro de Almeida. Processo e formas sócio-espaciais das cidades: propostas para avançar no debate. In: MELO E SILVA, Sylvio Bandeira de, (org.). Estudos sobre dinâmica territorial, ambiente e planejamento. João Pessoa: Grafset, 2011. 